\title{
Functional analysis of the SIERF01 gene in disease resistance to $S$. lycopersici
}

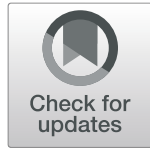

Huanhuan Yang, Fengyi Shen, Hexuan Wang, Tingting Zhao, He Zhang, Jingbin Jiang, Xiangyang Xu* and Jingfu Li

\begin{abstract}
Background: Tomato gray leaf spot caused by Stemphylium lycopersici (S. Iycopersici) is a serious disease that can severely hinder tomato production. To date, only Sm has been reported to provide resistance against this disease, and the molecular mechanism underlying resistance to this disease in tomato remains unclear. To better understand the mechanism of tomato resistance to S. Iycopersici, real-time quantitative reverse transcriptionpolymerase chain reaction (qRT-PCR)-based analysis, physiological indexes, microscopy observations and transgenic technology were used in this study.

Results: Our results showed that the expression of SIERF01 was strongly induced by S. lycopersici and by exogenous applications of the hormones salicylic acid (SA) and jasmonic acid (JA). Furthermore, overexpression of SIERF01 enhanced the hypersensitive response (HR) to S. lycopersici and elevated the expression of defense genes in tomato. Furthermore, the accumulation of lignin, callose and hydrogen peroxide $\left(\mathrm{H}_{2} \mathrm{O}_{2}\right)$ increased in the transgenic lines after inoculation with S. lycopersici. Taken together, our results showed that SIERFO1 played an indispensable role in multiple SA, JA and reactive oxygen species (ROS) signaling pathways to provide resistance to S. lycopersici invasion. Our findings also indicated that SIERF01 could activate the expression of the PR1 gene and enhance resistance to S. Iycopersici.

Conclusions: We identified the SIERF01 gene, which encodes a novel tomato AP2/ERF transcription factor (TF). Functional analysis revealed that SIERFO1 positively regulates tomato resistance to S. lycopersici. Our findings indicate that SIERF01 plays a key role in multiple SA, JA and ROS signaling pathways to provide resistance to invasion by $S$. lycopersici. The findings of this study not only help to better understand the mechanisms of response to pathogens but also enable targeted breeding strategies for tomato resistance to S. lycopersici.
\end{abstract}

Keywords: Tomato, SIERF01, Resistance response, S. Lycopersici

\section{Background}

During the long-term competitive relationship between plants and pathogens, plants have developed a series of defense mechanisms to resist the threat of pathogens, including bacteria, viruses, fungi and insects $[1,2]$. Two defense systems, PAMP-triggered immunity (PTI) and effector-triggered immunity (ETI), have been established

\footnotetext{
*Correspondence: xxy@126.com; huanyaya0126@sina.com College of Horticulture and Landscape Architecture, Northeast Agricultural University, Mucai Street 59, Xiangfang District, Harbin 150030, China
}

to prevent pathogenic invasion [3]. Many early signaling components of PTI and ETI activate a series of downstream integrated defense responses to prevent further damage [4]. In fact, substantial overlap of defense responses occur between PTI and ETI [5].

The various defensive signaling responses include reactive oxygen species (ROS) bursts and callose and lignin accumulation and lead to localized cell and tissue death $[6,7]$, which is referred to as the hypersensitive response (HR), at the site of pathogenic invasion to limit pathogen growth [8-10]. Therefore, the HR is associated

(c) The Author(s). 2020 Open Access This article is licensed under a Creative Commons Attribution 4.0 International License, which permits use, sharing, adaptation, distribution and reproduction in any medium or format, as long as you give appropriate credit to the original author(s) and the source, provide a link to the Creative Commons licence, and indicate if changes were made. The images or other third party material in this article are included in the article's Creative Commons licence, unless indicated otherwise in a credit line to the material. If material is not included in the article's Creative Commons licence and your intended use is not permitted by statutory regulation or exceeds the permitted use, you will need to obtain permission directly from the copyright holder. To view a copy of this licence, visit http://creativecommons.org/licenses/by/4.0/ The Creative Commons Public Domain Dedication waiver (http://creativecommons.org/publicdomain/zero/1.0/) applies to the data made available in this article, unless otherwise stated in a credit line to the data. 
with resistance gene ( $R$ gene)-triggered resistance, leading to localized cell and tissue death with corresponding downstream defense responses [11-13]. As a chemically reactive molecule, hydrogen peroxide $\left(\mathrm{H}_{2} \mathrm{O}_{2}\right)$ can induce the HR [14], which is associated with subsequent lignin and callose accumulation, limiting the growth of pathogens by strengthening cell walls.

If plant defense responses are induced at the site of infection, the systemic defense response is activated in other plant tissues to prevent further invasion by the pathogen. Systemic acquired resistance (SAR) is characterized by long-lasting, broad-spectrum effects [15]; these effects can be triggered by PTI- and ETImediated pathogen recognition and are related to the levels of salicylic acid (SA) in local cells and distant tissues. Previous studies have shown that the defense hormone SA plays an essential role in the SAR signaling pathway by inducing SAR-related gene expression via the regulatory protein NPR1 and a transcriptional coactivator [16].

Gray leaf spot disease, which is caused by Stemphylium lycopersici and is destructive fungal disease of plant species such as pepper, cotton, spinach and eggplant, is considered a major factor limiting the yield and quality of cultivated tomato fruit worldwide [17]. However, effective methods to control this disease are unavailable. Hence, the development of resistant cultivars is the most efficient strategy to control the gray leaf spot. Only the incompletely dominant gene Sm provides strong resistance to $S$. lycopersici [18]. Identification of other disease $\mathrm{R}$ genes and further application of these genes are urgently needed. In addition, the mechanism underlying the resistance of tomato to S. lycopersici remains poorly understood. Therefore, identification of the molecular mechanism underlying the $S m$-mediated resistance response to $S$. lycopersici and other $\mathrm{R}$ genes is urgently needed for the breeding of resistant tomato cultivars.

AP2/ERF-like transcription factors (TFs) have been shown to play an important role in disease resistance to various pathogens [19]. To date, a total of 137 ERF domain-containing proteins have been identified in the tomato genome, most of which are involved in the response to biotic and abiotic stress or in response to hormones; however, only a few of these proteins have been characterized [20]. Evidence has indicated that ERF proteins induce the expression of pathogenesis-related $(P R)$ genes by interacting with GCC boxes in the response to pathogens [21]. In tomato, Pti4-6 and LeERF1 interact with GCC boxes and regulate the expression of $P R$ genes [22]. In addition, ERF1 is transcriptionally regulated by pathogens, ethylene (ET), and jasmonic acid (JA) and is induced synergistically by ET and JA. It is known that the SA signal transduction pathway can act antagonistically with the ET/JA pathway. Interestingly, the expression of Pti4 and AtERF1 is induced by SA as well as by JA and ET $[23,24]$. These findings indicate that Pti4, Pti5 and Pti6 indirectly regulate the SA response and that the expression of Pti4/5/6 in Arabidopsis enhances the expression level of the SA-regulated PR1 and PR2 genes [11].

In this study, in attempts to better understand the mechanism underlying resistance to $S$. lycopersici in tomato, a novel tomato AP2/ERF TF, SlERF01, was identified. Our data showed that SIERFO1 is directly or indirectly involved in the defense response to $S$. lycopersici in tomato via multiple signaling regulatory networks. This study not only revealed the preliminary function of SlERFO1 but also provides a new $\mathrm{R}$ gene resource for cultivating resistant tomato varieties.

\section{Results \\ Cloning and phylogenetic analysis of SIERF01}

The full-length CDS of SlERFO1 was cloned by PCR using CDNA derived from tomato (the PCR primers used are listed in Table S1). The CDS of SIERFO1 encodes a 240 amino acid protein that has one AP2/ ERF domain and belongs to the ERF TF B-3 family (Fig. 1a). Analysis of the conserved protein sequence database revealed that only the ERF domain is conserved between SIERFO1 and other ERF proteins (Fig. 1b). Further analysis showed that SIERFO1 shares low similarity with other ERF proteins in terms of their whole putative protein sequences; however, sequence alignment revealed a high degree of homology in the ERF domain regions. Thus, the phylogenetic analysis results showed that SIERFO1 may encode a novel ERF protein that participates in the disease resistance response.

\section{Subcellular localization of SIERF01}

A SIERF01-GFP fusion construct was developed. The SIERF01::GFP fusion construct was subsequently transformed into the A. tumefaciens GV3101 strain, with an empty GFP vector serving as a negative control. $N$. benthamiana leaves were then infected. The results showed that SIERFO1 localized to the nucleus (Fig. 2).

\section{SIERF01 improves disease resistance against S. lycopersici in tomato}

To identify the function of SIERFO1 in tomato resistance to $S$. lycopersici, overexpression and TRV-mediated VIGS vectors were constructed for further analysis. Three SIERF01-overexpressing tomato lines presenting the greatest expression (lines 5, 11 and 15) and 3 TRV 


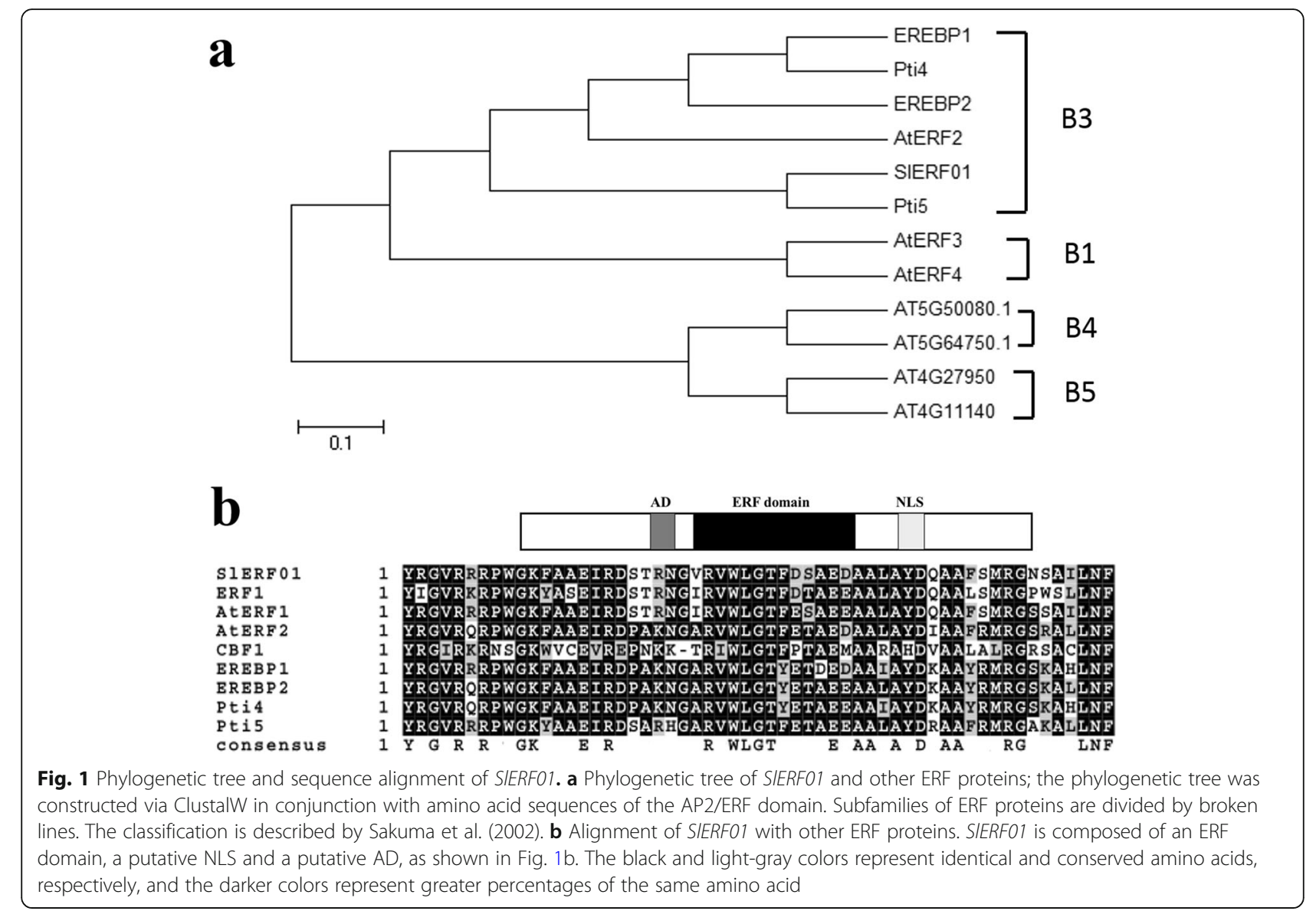

lines presenting the lowest expression (lines 3, 7 and 8) were ultimately generated for further analysis (Fig. 3). Overexpression of SIERF01 resulted in a typical HR-type phenotype at 3 dpi with $S$. lycopersici, and the susceptibility symptoms of transgenic SIERF01 overexpression (OE) plants were significantly less severe than those of susceptible plants. Compared with the plants transformed with the empty control vector (35 s::00), the transgenic lines exhibited enhanced resistance to $S$. lycopersici infection.

Furthermore, the HR was weaker and slower in SIERF01-silenced (TRV) plants than in the plants transformed with the empty control vector (TRV::00). Typical disease lesions were observed on SlERFO1-silenced

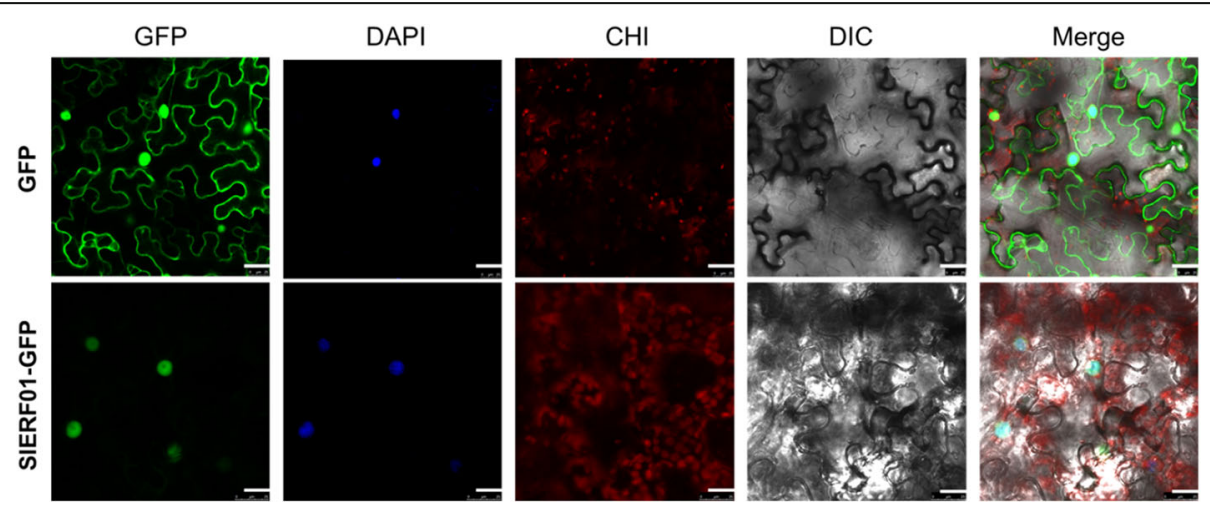

Fig. 2 Subcellular localization of SIERF01. SIERF01-GFP was localized in the nucleus, and GFP was localized throughout the cells. GFP: green fluorescence field, DAPI: 4',6-diamidino-2-phenylindole (DAPI) field (nuclear staining), CHI: chloroplast spontaneous fluorescence field, differential interference contrast (DIC): open field, Merge: superposition field. Light excitation wavelengths: GFP field: $488 \mathrm{~nm}$, DAPI field: $358 \mathrm{~nm}, \mathrm{CHI}$ field: $488 \mathrm{~nm}$. The merged images were obtained 2 days after agroinfiltration. Bars $=25 \mu \mathrm{m}$ 
a

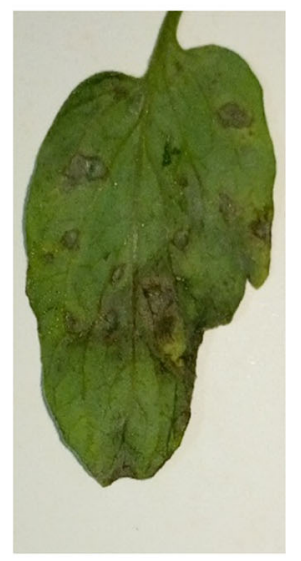

$35 \mathrm{~s}:: 00$

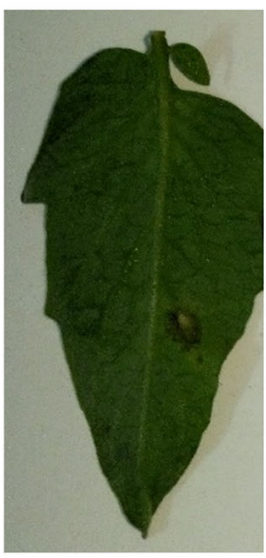

35s::SlERF01

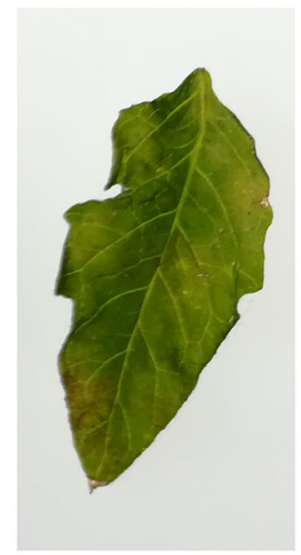

TRV::00

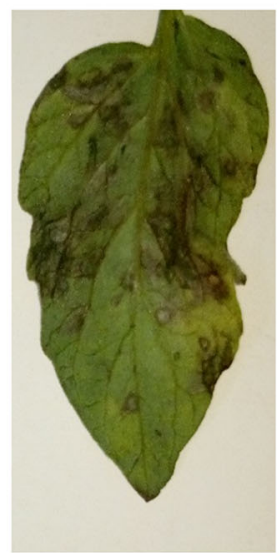

TRV::SIERF01

b
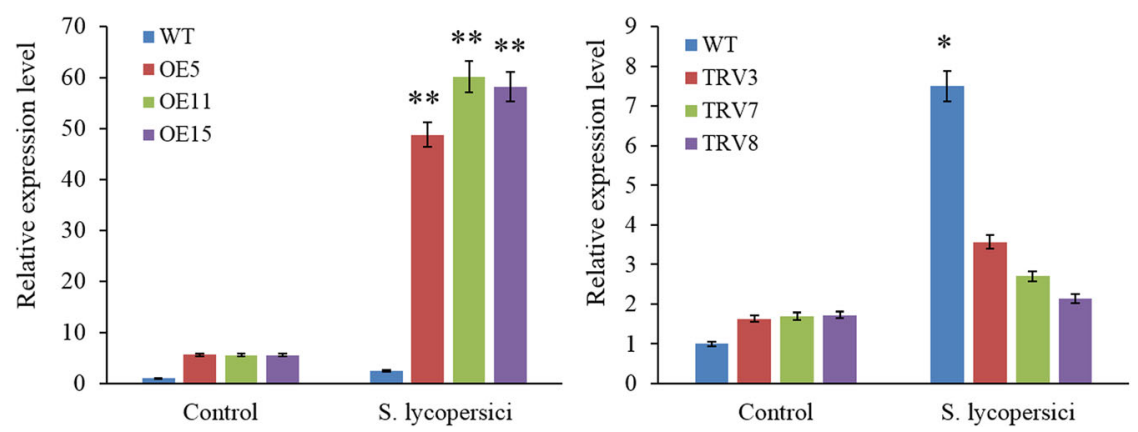

Fig. 3 Overexpression of SIERF01 enhances the disease resistance of tomato. a Disease symptoms in wild-type plants, SIERF01-overexpressing transgenic plants and silenced plants post inoculation with S. lycopersici. The transgenic (35 s::SIERF01) plants exhibited a highly resistant phenotype, and the silenced (TRV::SIERF01) plants exhibited severe disease symptoms. MT plants transformed with an empty vector (35 s::00); MO resistant plants transformed with a silencing vector (TRV::00). b Expression levels of SIERF01 in wild-type plants, OE plants and VIGS plants. Three OE lines (OE5, OE11 and OE15) and three VIGS (TRV) lines (TRV3, TRV7 and TRV8) were analyzed via qRT-PCR. Three biological replicates were included for each sample. The asterisks indicate significant differences in expression levels between transgenic lines and control lines ${ }^{* *}, P<0.01$; *, $P<0.05$, Student's t-test)

plants at $3 \mathrm{dpi}$, and no obvious susceptible symptoms were observed on the leaves of the TRV::00 plants (Fig. 3a). Furthermore, necrotic lesions and perforated center symptoms were evident on the leaves of the susceptible plants. These results indicated that SIERF01 promoted tomato resistance to S. lycopersici.

The effects of disease resistance in tomato were also evaluated by examining HR-related cell death and accumulation of $\mathrm{H}_{2} \mathrm{O}_{2}$, lignin, and callose by staining with trypan blue, $\mathrm{DAB}, \mathrm{TB}$ and $\mathrm{AB}$, respectively (Fig. 4). For trypan blue staining, a strong $\mathrm{HR}$ at 3 dpi with S. lycopersici was observed in SIERF01-overexpressing (35 s::SlERF01) plants. In contrast, no visible HR was observed in the empty vector (35 s::00) plants at $3 \mathrm{dpi}$; the hyphae gradually grew, and the lesions were aggravated and transparent. In contrast to those of the OE plants, the leaves of the SIERF01- silenced plants were sensitive to S. lycopersici infection. The HR was impaired in the TRV::SlERF01 plants compared with the TRV::00 plants infected with $S$. lycopersici at $3 \mathrm{dpi}$; hyphal spreading was observed, and the lesions were aggravated and perforated. However, a strong $\mathrm{HR}$ was observed on the leaves of the TRV::00 plants. Taken together, these results showed that SIERFO1 can trigger the HR in tomato leaves.

In addition, $\mathrm{H}_{2} \mathrm{O}_{2}$ production was observed in the leaves of the $35 \mathrm{~s}::$ SIERFO1 OE tomato plants by DAB staining (Fig. 4). At 3 dpi, compared with that in the TRV::00 plants, the $\mathrm{H}_{2} \mathrm{O}_{2}$ accumulation in the TRV:: SIERF01 plants was too weak to detect. $\mathrm{H}_{2} \mathrm{O}_{2}$ accumulation occurred earlier and stronger in the TRV::00 plants than in the TRV::SlERF01 plants. In contrast, the $\mathrm{H}_{2} \mathrm{O}_{2}$ accumulation occurred earlier and stronger in the $\mathrm{OE}$ 

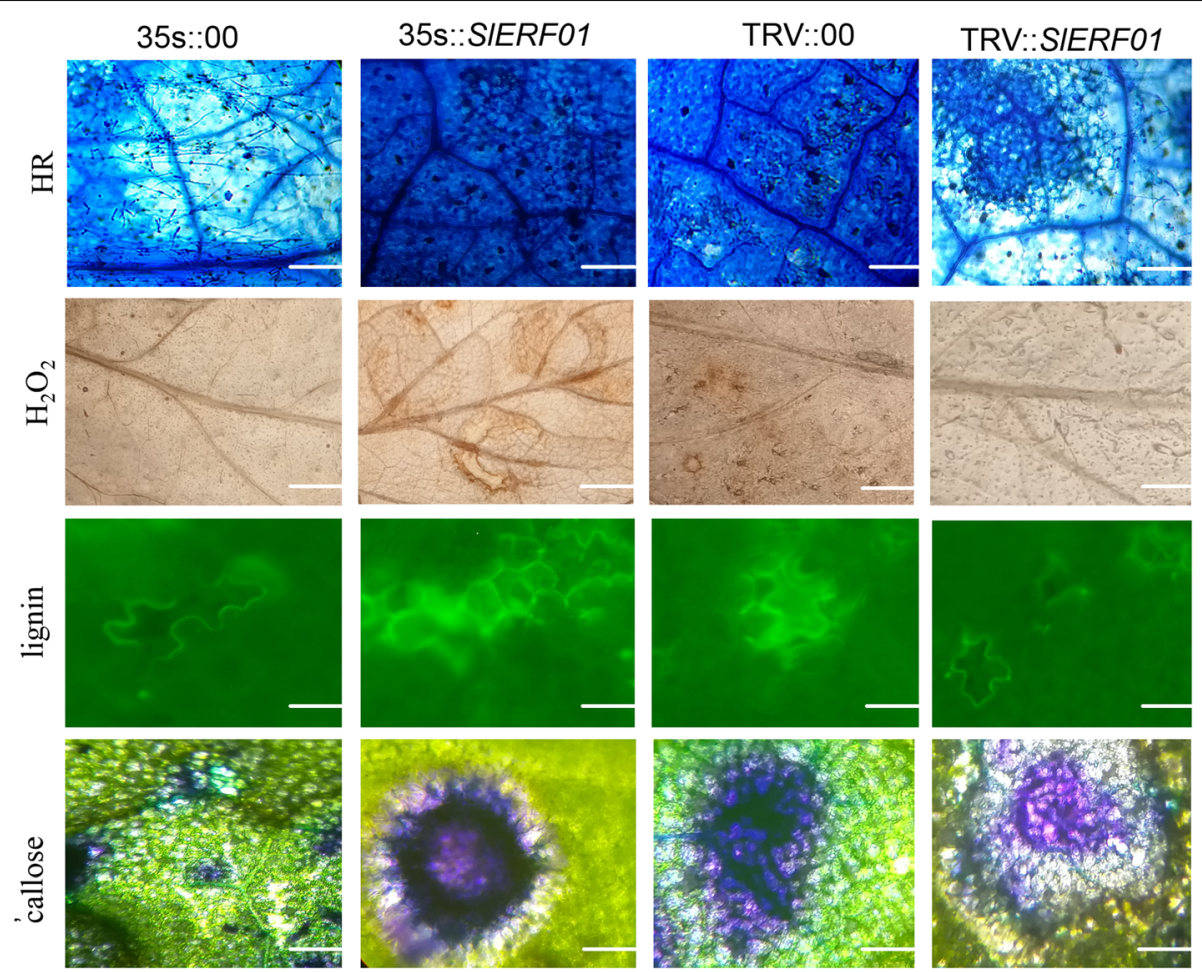

Fig. 4 Histopathological observations of HR-related cell death and accumulation of $\mathrm{H}_{2} \mathrm{O}_{2}$, lignin and callose. Similar results were obtained in three independent experiments. Bars $=25 \mu \mathrm{m}$

plants than in the $35 \mathrm{~s}: 00$ plants. These results indicated that SIERFO1 can induce $\mathrm{H}_{2} \mathrm{O}_{2}$ production as a defense response to $S$. lycopersici infection. To explore the potential mechanism further, lignin and callose production was analyzed in the $35 \mathrm{~s}:$ :SIERFO1 OE plants, TRV::SlERF01 plants and empty vector $(35 \mathrm{~s}::$ 00 and TRV::00) plants at $3 \mathrm{dpi}$. The accumulation of lignin and callose in the leaves of the $35 \mathrm{~s}::$ SlERF01 OE plants was greater than that in the leaves of the $35 \mathrm{~s}:: 00$ empty vector plants at 3 dpi (Fig. 4). However, the intensities and areas of fluorescence in the leaves of the TRV::SlERF01-silenced plants were weaker than those in the leaves of the TRV::00 plants. On the basis of all of the above results, we conclude that SIERFO1 overexpression enhances the resistance of tomato to S. lycopersici compared with that of control plants.

\section{Silencing of SIERF01 decreases the expression levels of the defense-related gene PR1 after infection with S. lycopersici} In previous transcriptome sequencing experiments, we found that the expression levels of the differentially expressed genes SlERFO1 and PR1 were significantly upregulated in the "plant hormone signal transduction" pathway [25]. In the present study, qRT-PCR was used to identify the regulatory relationship between SIERFO1 and $P R$ in the "plant hormone signal transduction" pathway. As shown in Fig. 7, once SIERFO1 was silenced, the expression level of $P R 1$ was significantly suppressed compared with that in the TRV::00 plants. In addition, compared with $35 \mathrm{~s}: 00$ plants, the expression levels of the PR1 gene were significantly upregulated in $35 \mathrm{~s}::$ SIERF01 OE plants (Fig. 7). Therefore, we proposed that SlERF01 enhances disease resistance to $S$. lycopersici by regulating the expression of the PR1 gene in tomato.

SIERF01 may require the SA and JA signaling pathways to enhance disease resistance in tomato

The above results show that overexpression of SlERF01 can improve disease resistance against $S$. lycopersici in tomato. In addition, our previous study showed that SIERFO1 is involved in the significantly enriched Kyoto Encyclopedia of Genes and Genomes (KEGG) pathway "plant hormone signal transduction". qRT-PCR was used to determine whether the transcript levels of SIERFO1 were associated with SA- and JA-induced resistance in resistant plants during SIERFO1 infection. Compared with the control (watersprayed) plants, plants treated with $0.2 \mathrm{mM}$ exogenous SA presented approximately 34-fold (in MO resistant plants) and 76-fold (in OE transgenic plants) increases in transcript levels, respectively (Fig. 5). After SA treatment, the expression of SIERFO1 was significantly upregulated and peaked at $24 \mathrm{~h}$; this gene expression 
SA

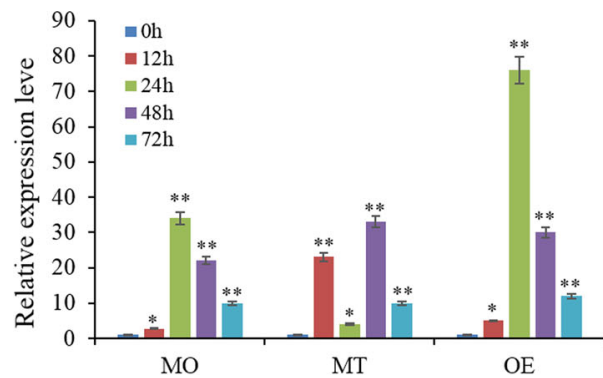

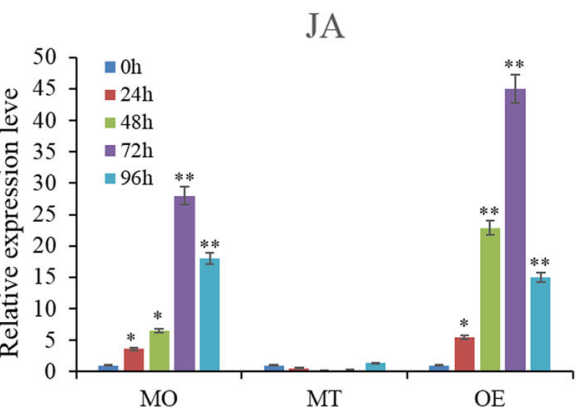

Fig. 5 Resistance induced by exogenous SA and JA in response to S. lycopersici infection in tomato. MO: resistant cultivar (Motelle), MT: control cultivar (Micro-Tom); OE: overexpression plants. The asterisks indicate significant differences in expression levels between hormone-treated plants and control (water-sprayed) plants. Similar results were obtained in three independent experiments $\left(* *, P<0.01 ; *^{*}, P<0.05\right.$, Student's t-test)

pattern was displayed in response to SA induction in both $\mathrm{MO}$ resistant plants and $\mathrm{OE}$ transgenic plants. In the MT control material, the expression of SIERFO1 was upregulated at $12 \mathrm{~h}$ and $48 \mathrm{~h}$ after treatment with SA, with a rapid decline at $24 \mathrm{~h}$, exhibiting an irregular change. Therefore, in the MT control material, the expression of SIERFO1 was upregulated at different time points but did not exhibit the same pattern in response to SA induction.

Similarly, treatment with JA also significantly enhanced the expression of SlERF01, whose peak expression level was 28 -fold (in MO resistant plants) and 45-fold (in OE transgenic plants) greater than that in the control plants. These results showed that SIERFO1 could be significantly upregulated by $\mathrm{SA}$ and JA treatment. In the MO resistant material, the expression of SIERFO1 was upregulated in response to JA induction. However, the expression of SlERF01 was not significantly upregulated at different time points in MT and did not respond to JA induction.

It is well known that SA and JA play important roles in the plant defense response to pathogens. To analyze the hormone response to $S$. lycopersici infection, liquid chromatography-mass spectrometry (LC-MS) was performed to measure the JA and SA contents in T1generation SIERFO1-overexpressing plants. The SA and JA levels of the T1-generation SIERFO1-overexpressing tomato plants were significantly greater than those of the control plants after inoculation with $S$. lycopersici (Fig. 6). After inoculation, the SA levels in the SIERF01-overexpressing plants were 5-fold greater than those in the empty vector plants, and the JA levels were approximately 3 -fold greater than those in the empty vector plants (Fig. 6). Thus, overexpression of SIERFO1 could significantly enhance the production of SA and JA, again indicating that SIERFO1 probably participates in both the SA and JA signaling pathways to improve the disease resistance of tomato to $S$. lycopersici.

\section{Discussion}

SIERF01 is a novel tomato AP2/ERF TF that is localized in the nucleus

To date, approximately 137 genes that encode proteins with conserved AP2/ERF domains have been identified in the tomato genome, and AP2/ERF proteins play an important role in the transcriptional regulation of a
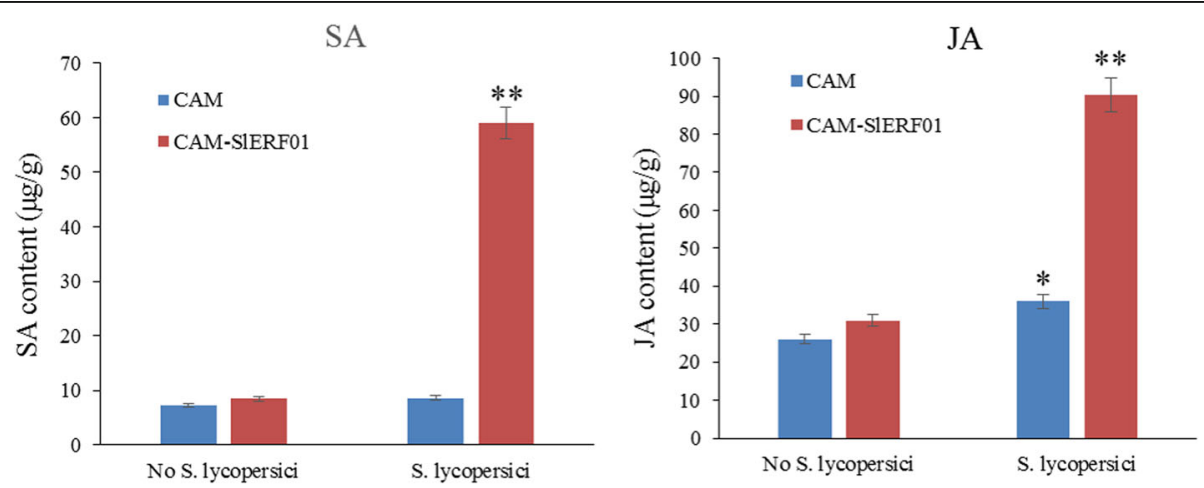

Fig. 6 SA and JA hormone levels in SIERF01-overexpressing lines. The asterisks indicate significant differences in the expression levels between transgenic lines and controls. The data are from three independent experiments (**, $P<0.01 ;{ }^{*}, P<0.05$, Student's t-test) 
variety of abiotic and biotic stress responses. Previous studies have shown that A-subgroup TFs are involved in the regulation of abiotic stress responses. However, nearly all the AP2 genes of the B subgroup have important functions in the biotic stress response. Furthermore, an increasing number of B-subfamily genes have been identified as being involved in resistance to bacterial, fungal and viral diseases [26].

In the present study, SIERFO1 was isolated from tomato, and its expression was shown to be upregulated after S. lycopersici treatment. In addition, phylogenetic analysis revealed that SIERFO1 belonged to the B-3 subfamily of ERF proteins, and a few B-3 subfamily members have been shown to regulate plant disease resistance [27]. Analysis of the conserved protein sequences in SIERFO1 revealed a low similarity to ERF1; however, the sequence homology was very high in the ERF domain regions (Fig. 1b). Our results showed that the cDNA of SIERFO1 probably encodes a novel ERF protein that is involved in the disease resistance response. Subcellular localization analysis showed that SIERF01 is a nuclear-localized protein, which is consistent with the results of previous studies on many ERF proteins.

\section{SIERF01 enhances tomato resistance to S. lycopersici}

It is well known that overexpression of ERFs can enhance plant disease resistance to fungi, bacteria, and viruses. Previous studies have shown that the overexpression of AaERF1 can positively regulate Artemisia annua resistance to Botrytis cinerea [28]. Furthermore, studies have shown that rice plants expressing the tobacco OPBP1 gene exhibit enhanced resistance to Magnaporthe grisea and Rhizoctonia solani [29].

The results of our present study showed that overexpression of SIERFO1 could significantly enhance resistance to $S$. lycopersici infection compared with that of control plants. Typical disease lesions were observed on SIERFO1-silenced plants, with no obvious susceptibility symptoms observed on TRV::00 plants. Moreover, studies have indicated that the $\mathrm{HR}$ and the accumulation of $\mathrm{H}_{2} \mathrm{O}_{2}$, lignin and callose are stronger in resistant cultivars than in susceptible cultivars, leading to improved disease resistance [30, 31]. Consistent with these previous studies, our study showed that overexpression of SIERFO1 not only led to HR-induced cell death but also increased the accumulation of $\mathrm{H}_{2} \mathrm{O}_{2}$, lignin and callose in transgenic tomato plants compared with control plants. These results indicated that SIERFO1 may also participate in resistance against $S$. lycopersici via ROS signaling (Fig. 8).
SIERF01 positively regulates the expression of $P R 1$ and enhances tomato disease resistance

Some ERF TFs, such as OsERF1, Pti4 and AtERF1, were recently suggested to play a role in the disease resistance response. As discussed in the introduction, overexpression of ERFs in plants can enhance plant disease resistance by regulating $P R$ gene expression [32]. The regulation of $P R$ gene expression by ERF TFs by binding to GCC boxes or to DRE/CRT cis-acting elements within gene promoter regions has been extensively studied [33-35]. Furthermore, studies have shown that sequences flanking GCC boxes affect binding efficiency, suggesting that multiple ERFs probably regulate various gene sets [36]. Therefore, ERFs may directly or indirectly regulate PR gene expression and enhance plant resistance to disease. Here, we also showed that overexpression of the SIERFO1 gene upregulated the expression of the PR1 gene and enhanced the tomato resistance to $S$. lycopersici.

\section{SIERF01 may require the SA and JA signaling pathways to enhance disease resistance in tomato}

In previous transcriptome sequencing experiments, we found that SIERF01 expression was induced by S. lycopersici in both resistant and susceptible materials and was highly upregulated in the resistant material after inoculation with S. lycopersici [25]. Furthermore, SA and JA are important signaling molecules that are involved in the disease resistance response to biotic and abiotic stress $[37,38]$. Our results showed that the expression of SIERF01 could be induced by exogenous SA in MO resistant plants and OE transgenic plants, suggesting that SIERF01 is probably the responsive component of the SA signaling pathways. Previous studies have also shown that exogenous application of SA can induce the expression of $P R$ genes and enhance resistance to multiple pathogens [39]. Our data were consistent with previous findings in which ERF1 was responsive to ET and SA through activated expression of downstream $P R$ genes [19]. However, the expression of SIERFO1 exhibited an irregular pattern and was downregulated in MT susceptible plants at $24 \mathrm{~h}$ after SA treatment, indicating that SIERF01 presented distinct expression characteristics between resistant plants and susceptible plants. SIERFO1 may be involved in crosstalk in response to pathogen attack via synergistic interactions of various signaling pathways. These results were consistent with the regulation of AhRRS5 differing between resistant and susceptible peanut varieties [40]. In addition, the SA and JA/ (ET) signaling pathways were identified as being antagonistic or synergistic in the disease resistance response [41-43]. Previous studies have shown that OsERF1 integrates the SA and JA signaling pathways in the defense response against pathogens [44]. Our results consistently 
showed that SIERFO1 was also induced by exogenous JA, suggesting that SIERFO1 probably plays a role in mediating communication between the SA and JA signaling pathways. Previous studies have shown that the ROS and SA pathways have parallel functions to ensure optimal induction of SAR [45]. Combined with the results of the above studies, our results showed that SlERFO1 not only responded to SA and JA but also increased the accumulation of $\mathrm{H}_{2} \mathrm{O}_{2}$, lignin and callose in transgenic tomato plants. Here, we propose that SIERFO1 plays a critical role in the crosstalk among SA, JA and ROS, providing resistance to $S$. lycopersici invasion (Fig. 8).

\section{Conclusions}

In this study, we identified SlERFO1 as a novel gene in tomato encoding an AP2/ERF TF that localizes to the nucleus. Analyses of overexpression and gene silencing data revealed that SIERFO1 positively regulates tomato resistance to $S$. lycopersici. Interestingly, SlERF01 plays a key role in multiple SA, JA and ROS signaling pathways to provide resistance to invasion by $S$. lycopersici. Preliminary functional analysis demonstrated that SIERFO1 induces disease resistance by upregulating the expression of the PR1 gene. This study ultimately provides valuable resources for future studies of the molecular mechanisms involved in disease resistance and breeding strategies for tomato varieties.

\section{Methods}

\section{Plant materials and S. lycopersici inoculation}

Tomato plants of the resistant cultivar Motelle (MO) were provided by the Chinese Academy of Agricultural Sciences. Seedlings of the transgenic line Micro-Tom (MT) and Nicotiana benthamiana were obtained from our laboratory. Tomato and tobacco plants were subsequently grown in a greenhouse at $25-28{ }^{\circ} \mathrm{C}$ and $60 \%$ relative humidity under a $14 \mathrm{~h} / 10 \mathrm{~h}$ light/dark photoperiod.

S. lycopersici was isolated from tomato plants and plated on potato dextrose agar (PDA) in Petri dishes at $25-28^{\circ} \mathrm{C}$ for 10 days under a $12 \mathrm{~h} / 12 \mathrm{~h}$ photoperiod. Afterward, 4-week-old tomato seedlings of MO, Moneymaker and MT were inoculated with a conidial suspension $\left(1 \times 10^{4}\right.$ conidia $\left.\mathrm{mL}^{-1}\right)$, while control plants were sprayed with sterilized water. The plants were maintained in a greenhouse $\left(25-28^{\circ} \mathrm{C}\right)$ under a relative humidity of $>80 \%$. The disease indexes were evaluated post inoculation, and leaves were harvested at 0 and 3 days post inoculation (dpi) for further analysis.

\section{Gene cloning and bioinformatic analysis}

The $5^{\prime}$ - and $3^{\prime}$-ends of cDNA sequences were cloned by homologous recombination via PCR Cloning Kit. Specific primers used for the target sequence were designed via Primer 6.0 software, and the target gene SIERF01 was cloned via PCR implemented in accordance with the following reaction protocol: $94{ }^{\circ} \mathrm{C}$ for 3 min; 35 cycles of $94^{\circ} \mathrm{C}$ for $30 \mathrm{~s}, 60^{\circ} \mathrm{C}$ for $45 \mathrm{~s}$, and $72{ }^{\circ} \mathrm{C}$ for $30 \mathrm{~s} \mathrm{~kb}^{-1}$; and $72{ }^{\circ} \mathrm{C}$ for $10 \mathrm{~min}$. A partCAM-SLERF01 vector was constructed for the identification of positive clones. All the primers used in the study are shown in Table S1.

The SIERF01 sequence was examined by checking the NCBI Conserved Domain Database (CDD) (https://www. ncbi.nlm.nih.gov/Structure/cdd/wrpsb.cgi), and the identified sequences were analyzed via DNAMAN 5.0 (Data S2). A phylogenetic tree of the AP2/ERF family proteins of tomato was subsequently constructed by MEGA 5.2.

\section{Subcellular localization}

The full-length SLERFO1 open reading frame (ORF) without the termination codon was amplified via PCR in conjunction with a high-fidelity polymerase together with the primers GFP-SLERFO1-F and GFPSLERF01-R. A pCAM35::SLERF01-GFP fusion construct was prepared by inserting the PCR products into a pCAM35::GFP vector between its KpnI and XbaI sites. The pCAM35::GFP (control) and pCAM35::SLERF01-GFP vectors were subsequently transformed into Agrobacterium tumefaciens GV3101. Single clones were selected and then cultured in Luria-Bertani (LB) liquid media containing corresponding antibiotics. The transformed Agrobacterium cells were concentrated by centrifugation, after which they were harvested, diluted to an $\mathrm{OD}_{600}$ of 0.4 , and injected into $N$. benthamiana leaves via a syringe. Two days after agroinfiltration, the green fluorescent proteins (GFPs) were imaged by a laser scanning confocal microscope (FV10-ASW, Olympus).

\section{Transformation of tomato}

The full-length coding DNA sequence (CDS) of SIERFO1 was amplified via PCR and cloned into a part-CAM vector harboring XhoI and XbaI sites. A pCAM-SLERFO1 overexpression vector was constructed, and the pCAM-SIERFO1 recombinant plasmid and the pCAM plasmid were transferred into $A$. tumefaciens strain GV3101 (BioVector NTCC Inc., Beijing, China). The pCAM-SIERFO1 (overexpression) and pCAM (empty) vectors were transferred into the susceptible cultivar MT via a tomato genetic transformation technique [46]. Ten-day-old tomato seedlings were used as explants and precultured for 2 days on MR (Murashige and Skoog (MS) media 
supplemented with $0.2 \mathrm{mgl}^{-1}$ zeatin and $1.0 \mathrm{mgl}^{-1}$ indoleacetic acid (IAA), pH 5.8) media.

A single colony of A. tumefaciens was selected from LB liquid media that was supplemented with corresponding antibiotics. Bacterial cells were then collected, after which tomato cotyledons were immersed in the bacterial suspension for 3-5 min and cocultivated for 2 days. Infected cotyledons were transferred to suitable media and allowed to grow for 2 weeks, and the explants were subcultured every 3 weeks. After acclimatization, plantlets with well-developed roots were transplanted into soil.

Two different $A$. tumefaciens strains were used for virus-induced gene silencing (VIGS). One carried TRV1, which encoded viral proteins needed for replication and movement, while the other, TRV2, harbored the coat protein and sequence used for VIGS [47]. The target sequence of SIERFO1 was amplified via PCR with specific primers. After digestion with EcoRI and BamHI, the TRV vector was ligated to the PCR product. TRV:: SlERF01, TRV::00 and TRV::PDS vectors were constructed and propagated in LB media that containing 50 $\mathrm{mg} \mathrm{mL}^{-1}$ kanamycin. The recombinant plasmids were then transferred into A. tumefaciens strain GV3101, after which the transformed cells were cultured in induction media (10 mM 2-(N-morpholino) ethanesulfonic acid (MES), $10 \mathrm{mM} \mathrm{MgCl}_{2}, 2.50 \mu \mathrm{g} \mathrm{mL}^{-1}$ kanamycin, $100 \mu \mathrm{g}$ $\mathrm{mL}^{-1}$ rifampicin and $200 \mu \mathrm{M}$ acetosyringone) to an $\mathrm{OD}_{600}$ of 0.3 . Lst, TRV1 and TRV2 were mixed together at a volumetric ratio of $1: 1$ and incubated for $3 \mathrm{~h}$; MO plants at the 3-4-leaf stage were then infiltrated with each mixture via a $1 \mathrm{~mL}$ syringe containing approximately $0.5-1 \mathrm{~mL}$ of the Agrobacterium cell culture solution. The treated plants were sampled at indicated time points for further analysis, and 3 biological replicates were included in the test.

\section{Real-time quantitative reverse transcription-polymerase chain reaction (qRT-PCR) analysis and determination of physiological indexes}

Expression analysis of the overexpression and VIGS plants was performed via qRT-PCR. Total RNA was extracted from tomato leaves by TRIzol reagent [48]. cDNA was synthesized by a reverse transcription kit (TaKaRa) according to the manufacturer's instructions. The qRT-PCR system consisted of $10 \mu \mathrm{L}$ of $2 \times$ TransStart Top Green qPCR SuperMix (TransGen, China), $0.5 \mu \mathrm{L}$ of forward/reverse primers, and $2 \mu \mathrm{L}$ of cDNA template, and $\mathrm{ddH}_{2} \mathrm{O}$ was added to bring the total volume to $20 \mu \mathrm{L}$. The qRT-PCR program was as follows: $95^{\circ} \mathrm{C}$ for $10 \mathrm{~min}$, followed by 40 cycles of $95^{\circ} \mathrm{C}$ for $5 \mathrm{~s}, 62{ }^{\circ} \mathrm{C}$ for $15 \mathrm{~s}$ and $72^{\circ} \mathrm{C}$ for $30 \mathrm{~s}$. The $2^{-}$ $\triangle \triangle \mathrm{CT}$ method [49] was subsequently used to analyze the qRT-PCR data, with EF1 $\alpha$ serving as a reference gene [50]. The qRT-PCR primers used are listed in Table S1.

For exogenous hormone treatment, $0.2 \mathrm{mM} \mathrm{SA}$ and $0.4 \mathrm{mM}$ JA solutions were sprayed onto tomato plants (the control plants were sprayed with water) at different time points (SA: 0, 12, 24, 48 and $72 \mathrm{~h}$; JA: $0,24,48,72$ and $96 \mathrm{~h}$ ). The levels of the endogenous SA and JA hormones were measured via high-performance liquid chromatography (HPLC). SA and JA were extracted from the leaves according to a modified method described by Llugany et al. [51], after which their concentrations were measured by an AB SCIEX QTRAP 5500 instrument (USA) according to the manufacturer's instructions. Samples were collected from three individual plants for analyses of the SA content, JA content and gene expression. Data from three independent experiments were statistically analyzed according to Student's t-tests, and $P<0.05$ was considered statistically significant.

\section{Microscopy observations}

Trypan blue staining [52], 3,3-diaminobenzidine (DAB) staining, toluidine blue (TB) staining and aniline blue (AB) staining were used to observe the progression of $S$. lycopersici infection and the production of $\mathrm{H}_{2} \mathrm{O}_{2}$, lignin and callose in SIERFO1-overexpressing and SIERFO1VIGS plants. The leaves were collected at 0 and 3 days after inoculation.

Cell death was observed by the use of TB staining, with destaining in Farmer's solution (95\% ethanol: chloroform:acetic acid at a volumetric ratio of $6: 3: 1$ ) for $3 \mathrm{~h}$ and boiling in $0.1 \%$ trypan blue solution at $65^{\circ} \mathrm{C}$ for $2 \mathrm{~h}$, followed by transfer to a saturated chloral hydrate solution for $4 \mathrm{~h}$. The leaves were ultimately observed under a light microscope.

The production of $\mathrm{H}_{2} \mathrm{O}_{2}$ was detected via DAB staining [53]. Infected tomato leaves were incubated in $0.1 \%$ $\mathrm{DAB}$ solution at room temperature in the dark for $12 \mathrm{~h}$ and then boiled in a 96\% ethanol solution for $10 \mathrm{~min}$. The leaves were ultimately observed under a light microscope. Lignin was observed by the use of the TB staining method [54]. The infected tomato leaves were placed in formaldehyde:acetic acid:ethanol (FAA) solution for $24 \mathrm{~h}$ and then stained with a $0.05 \%$ TB solution. The leaves were subsequently observed under a light microscope. Callose was detected by the use of the $A B$ staining method [55]. The infected tomato leaves were placed in FAA solution, cleared with $100 \%$ ethanol solution and then stained with $0.07 \mathrm{M} \mathrm{K}_{2} \mathrm{HPO}_{4}$ in a $0.01 \%$ $A B$ solution for $24 \mathrm{~h}$. The leaves were ultimately observed under a fluorescence microscope. Leaf samples were collected from three individual plants for analyses of the $\mathrm{HR}, \mathrm{H}_{2} \mathrm{O}_{2}$ production, and lignin and callose accumulation. 

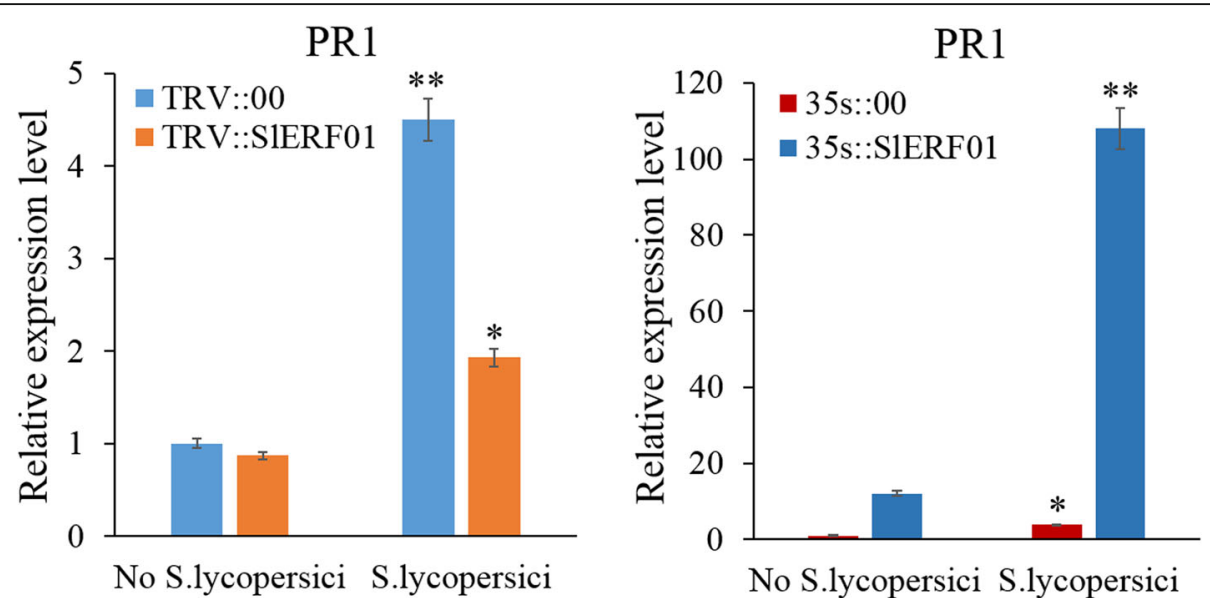

Fig. 7 The expression level of the defense-related gene PR1 in SIERF01-silenced and SIERF01-overexpressing plants. TRV::00, empty vector plant; TRV::SIERF01, SIERF01-silenced plant; 35 s::00, plant transformed with an empty vector; 35 s::SIERF01, OE plants. The asterisks indicate significant differences in the expression levels between silenced lines and control lines. Similar results were obtained in independent experiments $(* *, P<$ $0.01 ;{ }^{*}, P<0.05$, Student's t-test)

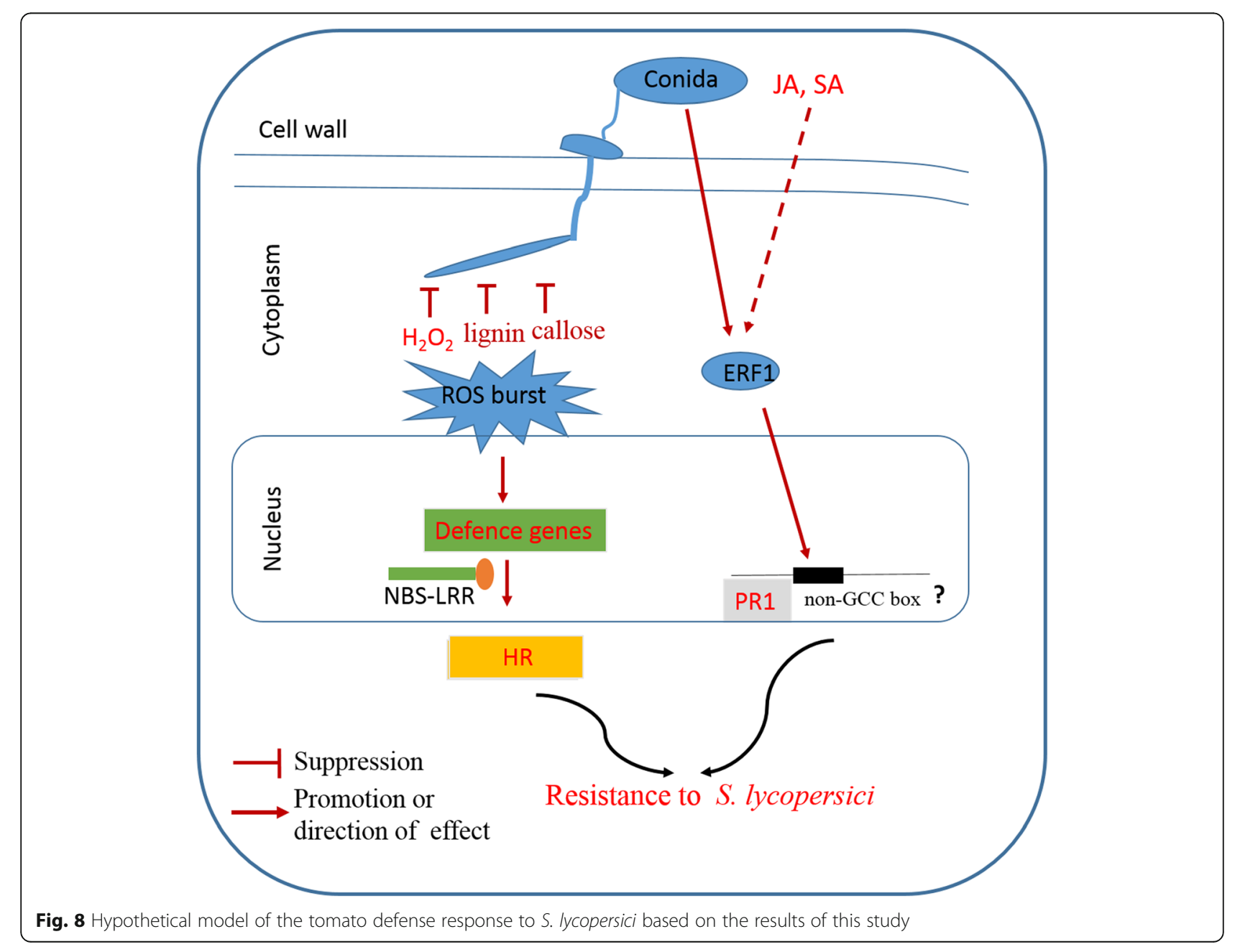




\section{Supplementary information}

Supplementary information accompanies this paper at https://doi.org/10. 1186/s12870-020-02588-w.

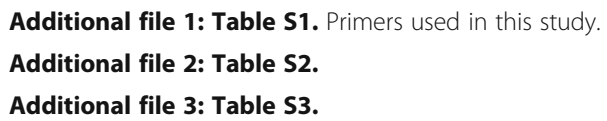

Additional file 1: Table S1. Primers used in this study. Additional file 2: Table S2.

Additional file 3: Table S3.

\section{Abbreviations}

S. Iycopersici: Stemphylium lycopersici; PTI: PAMP-triggered immunity; ETI: Effector-triggered immunity; ROS: Reactive oxygen species; HR: Hypersensitive response; SAR: Systemic acquired resistance; PR1: Pathogenesis-related protein 1-like; $R$ gene: Resistance gene; qRTPCR: Real-time quantitative reverse transcription-polymerase chain reaction; VIGS: Virus-induced gene silencing; SA: Salicylic acid; JA: Jasmonic acid

\section{Acknowledgments}

We acknowledge Prof. Jingfu Li for his efforts in revising the manuscript. We also thank Junming Li (Chinese Academy of Agricultural Sciences, China), who provided the tomato cultivars (the resistant cultivar $\mathrm{MO}$ and the susceptible cultivar Moneymaker).

\section{Authors' contributions}

$J L$ and XX conceived and designed the experiments. FS and HW performed RNA extraction and expression pattern analysis. $\mathrm{HZ}$ and $\mathrm{TZ}$ prepared the plant materials and artificial inoculation. JJ performed the determination of JA and SA. HY performed the transformation of tomato, subcellular localization and wrote the manuscript. All authors reviewed and approved the final manuscript.

\section{Funding}

This work was supported by the "Young Talents" Project of Northeast Agricultural University (18QC08) for the design of the study and collection, the National Key R\&D Plan for the 13th Five-Year Plan (2016YFD01703) for the interpretation of data, the National Key R\&D Program of China (2017YFD0101900) for experimental reagent, and the China Agriculture Research System (CARS-23-A-16) for the language editing.

\section{Availability of data and materials}

The datasets supporting the results of this study are included with the article and its additional files (Table S2 and Table S3).

The materials are available upon request by contacting the corresponding author.

The data concerning the phylogenetic tree and sequence alignment of SIERF01 are shown in Fig. 1.

The data concerning the subcellular localization of SIERFO1 are shown in Fig. 2.

The data concerning the overexpression of SIERF01 in tomato are shown in Fig. 3.

The data concerning the histopathological observations of HR-related cel death and accumulation of $\mathrm{H}_{2} \mathrm{O}_{2}$, lignin and callose are shown in Fig. 4. The data concerning the resistance induced by exogenous SA and JA against S. lycopersici infection in tomato are shown in Fig. 5.

The data concerning the hormone level analysis of the control and transgenic lines are shown in Fig. 6.

The data concerning the expression levels of SIERF01 and PR1 are shown in Fig. 7.

The data concerning the hypothetical model of the tomato defense response to S. lycopersici are shown in Fig. 8.

\section{Ethics approval and consent to participate}

Not applicable.

\section{Consent for publication}

Not applicable.

\section{Competing interests}

The authors declare that they have no competing interests.
Received: 14 February 2020 Accepted: 9 August 2020

Published online: 15 August 2020

\section{References}

1. Henry E, Yadeta KA, Coaker $G$, et al. Recognition of bacterial plant pathogens: local, systemic and transgenerational immunity. New Phytol. 2013;199(4):908-15.

2. Jones JDG, Dangl JL. The plant immune system. Nature. 2006;444(7117): 323-9.

3. Thomma BPHJ, Nurnberger T, Joosten MHAJ. Of PAMPs and effectors: the blurred PTI-ETI dichotomy. Plant Cell. 2011;23(1):4-15.

4. Cheng X, Tian CJ, Li AN, et al. Advances on molecular mechanisms of plantpathogen interactions. Hereditas. 2012;34(2):134-44.

5. Tsuda K, Sato M, Glazebrook J, et al. Interplay between MAMP-triggered and SA-mediated defense responses. Plant J. 2008:53:763-75.

6. Zvereva AS, Pooggin MM. Silencing and innate immunity in plant defense against viral and non-viral pathogens. Viruses. 2012;4(11):2578-97.

7. Torres MA, Jones JD, Dangl JL. Reactive oxygen species signaling in response to pathogens. Plant Physiol. 2006;141(2):373-8.

8. Vleeshouwers VG, van Dooijeweert W, Govers F, Kamoun S, Colon LT. The hypersensitive response is associated with host and nonhost resistance to Phytophthora infestans. Planta. 2000;210(6):853-64.

9. Keen NT. Gene-for-gene complementarity in plant-pathogen interactions. Annu Rev Genet. 1990;24(1):447-63.

10. Zhang J, Lu H, Li X, et al. Effector-triggered and pathogen-associated molecular pattern-triggered immunity differentially contribute to basal resistance to Pseudomonas syringae. Mol Plant-Microbe Interact. 2010;23(7): 940-8.

11. Baker B, Zambryski P, Staskawicz B, Dinesh-Kumar SP. Signaling in plantmicrobe interactions. Science. 1997;276(5313):726-33.

12. De Wit PJGM. Pathogen avirulence and plant resistance: a key role for recognition. Trends Plant Sci. 1997;2(12):452-8.

13. Wang LC, Li H, Ecker JR, et al. Ethylene biosynthesis and signaling networks. Plant Cell. 2002;14(Suppl):131-51.

14. Lehmann S, Serrano ML, Haridon F, et al. Reactive oxygen species and plant resistance to fungal pathogens. Phytochemistry. 2015;112:54-62.

15. Durrant WE, Dong X. Systemic acquired resistance. Annu Rev Phytopathol. 2004;42:185-209.

16. $\mathrm{Fu} Z \mathrm{ZQ}$, Dong $X$. Systemic acquired resistance: turning local infection into global defense. Annu Rev Plant Biol. 2013;64(1):839-63.

17. Simmons EG. Perfect states of Stemphylium IV. Harv Pap Bot. 2001;61(1): 199-208.

18. Hanson P, Lu SF, Wang JF, et al. Conventional and molecular markerassisted selection and pyramiding of genes for multiple disease resistance in tomato. Sci Hortic. 2016:201:346-54.

19. Solano R, Stepanova A, Chao Q, et al. Nuclear events in ethylene signaling: a transcriptional cascade mediated by ETHYLENE-INSENSITIVE3 and ETHYLE NE-RESPONSE-FACTOR1. Genes Dev. 1998:12(23):3703-14.

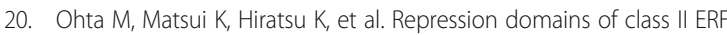
transcriptional repressors share an essential motif for active repression. Plant Cell. 2001;13(8):1959-68

21. Gu YQ, Wildermuth MC, Chakravarthy S, et al. Tomato transcription factors pti4, pti5, and pti6 activate defense responses when expressed in Arabidopsis. Plant Cell. 2002:14:817-31.

22. Tournier B, Sanchez-Ballesta MT, Jones B, et al. New members of the tomato ERF family show specific expression pattern and diverse DNA-binding capacity to the GCC box element. FEBS Lett. 2003;550:149-54.

23. Gu YQ, Yang C, Thara VK, et al. Pti4 is induced by ethylene and salicylic acid, and its product is phosphorylated by the Pto kinase. Plant Cell. 2000;12:77186.

24. Onate-Sanchez L, Singh KB. Identification of Arabidopsis ethyleneresponsive element binding factors with distinct induction kinetics after pathogen infection. Plant Physiol. 2002;128:1313-22.

25. Yang HH, Zhao $\Pi$, Jiang JB, et al. Transcriptome analysis of the Smmediated hypersensitive response to Stemphylium lycopersici in tomato. Front Plant Sci. 2017:8:1257-71

26. Nakano T, Suzuki K, Fujimura T, et al. Genome-wide analysis of the ERF gene family in Arabidopsis and rice. Plant Physiol. 2006;140(2):411-32.

27. Gutterson N, Reuber TL. Regulation of disease resistance pathways by AP2/ ERF transcription factors. Curr Opin Plant Biol. 2004;7(4):465-71. 
28. Yang KY, Liu Y, Zhang S. Activation of a mitogen-activated protein kinase pathway is involved in disease resistance in tobacco. Proc Natl Acad Sci. 2001;98(2):741-6.

29. Melech-Bonfil S, Sessa G. Tomato MAPKKKE is a positive regulator of celldeath signaling networks associated with plant immunity. Plant J. 2010; 64(3):379-91.

30. Romero D, Eugenia Rivera M, Cazorla FM, et al. Comparative histochemical analyses of oxidative burst and cell wall reinforcement in compatible and incompatible melon-powdery mildew (Podosphaera fusca) interactions. J Plant Physiol. 2008;165(18):1895-905.

31. Chen Y, Zhang S, Kang Z, et al. Accumulation and distribution of hydrogen peroxide in interaction between sugarbeet plant and sugarbeet necrotic yellow vein virus. Acta Agron Sin. 2012;38(5):865-70.

32. Vos IA, Moritz L, Pieterse CMJ, et al. Impact of hormonal crosstalk on plant resistance and fitness under multi-attacker conditions. Front Plant Sci. 2015; 6:639-52.

33. Sakuma Y, Liu Q, Dubouzet JG, Yamaguchi-Shinozaki K. DNA-binding specificity of the ERF/AP2 domain of Arabidopsis DREBs, transcription factors involved in dehydration- and cold-inducible gene expression. Biochem Biophys Res Commun. 2002;290(3):998-1009.

34. Lorenzo $\mathrm{O}$, Piqueras $\mathrm{R}$, Jose J, et al. ETHYLENE RESPONSE FACTOR1 integrates signals from ethylene and jasmonate pathways in plant defense. Plant Cell. 2003;15:165-78.

35. Zuo KJ, Qin J, Zhao JY, et al. Over-expression GbERF2 transcription factor in tobacco enhances brown spots disease resistance by activating expression of downstream genes. Gene. 2007;391(1-2):80-90.

36. Romero I, Vazquez-Hernandez M, Escribano Ml, et al. Expression profiles and DNA-binding affinity of five ERF genes in bunches of Vitis vinifera CV. Cardinal treated with high levels of $\mathrm{CO} 2$ at low temperature. Front Plant Sci. 2016;7:370-83

37. Divi UK, Rahman T, Krishna P. Brassinosteroid-mediated stress tolerance in Arabidopsis shows interactions with abscisic acid, ethylene and salicylic acid pathways. BMC Plant Biol. 2010;10(1):151-65.

38. Ton J, Flors $V$, Mauch-Mani B. The multifaceted role of ABA in disease resistance. Trends Plant Sci. 2009;14(6):310-7.

39. Bari $R$, Jones JDG. Role of plant hormones in plant defence responses. Plant Mol Biol. 2009;69(4):473-88

40. Zhang $\mathrm{C}$, Chen $\mathrm{H}$, Cai T, et al. Overexpression of a novel peanut NBS-LRR gene AhRRS5 enhances disease resistance to Ralstonia solanacearum in tobacco. Plant Biotechnol J. 2016;15:39-55.

41. Van Loon LC, Rep M, Pieterse CMJ. Significance of inducible defense-related proteins in infected plants. Annu Rev Phytopathol. 2006;44(1):135-62.

42. Beckers GJM, Spoel SH. Fine-tuning plant defence signaling: salicylate versus jasmonate. Plant Biol. 2006;8(1):1-10.

43. Mur LAJ, Kenton P, Atzorn R, et al. The outcomes of concentration-specific interactions between salicylate and jasmonate signaling include synergy, antagonism, and oxidative stress leading to cell death. Plant Physiol. 2006; 140(1):249-62.

44. Nahar K, Kyndt T, Nzogela YB, et al. Abscisic acid interacts antagonistically with classical defense pathways in rice-migratory nematode interaction. New Phytol. 2012;196:901-13.

45. Wang C, El-Shetehy M, Shine MB, et al. Free radicals mediate systemic acquired resistance. Cell Rep. 2014;7(2):348-55

46. Ouyang B. Chen, et al. transformation of tomatoes with osmotin and chitinase genes and their resistance to Fusarium wilt. J Hortic Sci Biotechnol. 2005;80:517-22.

47. André C. Velásquez, Chakravarthy S, Martin GB. Virus-induced gene silencing (VIGS) in Nicotiana benthamiana and tomato. J Vis Exp. 2009;28(28):1-4.

48. Wu T, Qin ZW, Zhou XY, et al. Transcriptome profile analysis of floralsex determination in cucumber. J Plant Physiol. 2010;167(11):905-13.

49. Livak KJ, Schmittgen TD. Analysis of relative gene expression data using realtime quantitative PCR and the 2- $\Delta \Delta C T$ method. Methods. 2001;25:402-8.

50. Rotenberg D, Thompson TS, German TL, et al. Methods for effective realtime RT-PCR analysis of virus-induced gene silencing. J Virol Methods. 2006; 138(1-2):49-59.

51. Llugany M, Martin SR, Barceló J, et al. Endogenous jasmonic and salicylic acids levels in the cd-hyperaccumulator Noccaea (Thlaspi) praecox exposed to fungal infection and/or mechanical stress. Plant Cell Rep. 2013;32:1243-9.

52. Wang X, El Hadrami A, Adam LR, et al. Differential activation and suppression of potato defence responses by Phytophthora infestans isolates representing US-1 and US-8 genotypes. Plant Pathol. 2008;57(6):1026-37.
53. Thordal-Christensen $\mathrm{H}$, Zhang Z, Wei $\mathrm{Y}$, et al. Subcellular localization of $\mathrm{H}_{2} \mathrm{O}_{2}$ in plants. $\mathrm{H}_{2} \mathrm{O}_{2}$ accumulation in papillae and hypersensitive response during the barley-powdery mildew interaction. Plant J. 1997;11:1187-94.

54. O'Brian TP, Feder N, McCully ME. Polychromatic staining of plant cell walls by toluidine blue. Protoplasma. 1964:59:368-73.

55. Heath MC. Light and electron microscope studies of the interactions of host and non-host plants with cowpea rust-Uromyces phaseoli Var. vignae. Physiol Plant Pathol. 1974;4:403-14

\section{Publisher's Note}

Springer Nature remains neutral with regard to jurisdictional claims in published maps and institutional affiliations.
Ready to submit your research? Choose BMC and benefit from:

- fast, convenient online submission

- thorough peer review by experienced researchers in your field

- rapid publication on acceptance

- support for research data, including large and complex data types

- gold Open Access which fosters wider collaboration and increased citations

- maximum visibility for your research: over $100 \mathrm{M}$ website views per year

At BMC, research is always in progress.

Learn more biomedcentral.com/submissions 